\title{
Arthroscopic Repair of Dorsal Radiocarpal Ligament Tear - Report of Three Cases
}

\section{Reparación artroscópica de la rotura del ligamento dorsal radiocarpiano - Relato de tres casos}

\author{
${ }^{1}$ Orthopedics Service, Hospital Professor Doutor Fernando Fonseca, \\ Amadora, Portugal \\ 2 Orthopedics Service, Hospital da Cruz Vermelha Portuguesa, Lisboa, \\ Portugal \\ ${ }^{3}$ Orthopedics Service, Hospital Ortopédico de Sant'Ana, Parede, Portugal \\ ${ }^{4}$ Orthopedics Service, Hospital de São Francisco Xavier, Centro \\ Hospitalar de Lisboa Ocidental, Lisboa, Portugal
}

Catarina Neto Pereira1ำ Inês Pedro ${ }^{2,3(1)}$ Carla Ricardo Nunes $2,4(0$

\begin{abstract}
Address for correspondence Carla Ricardo Nunes, MD, Hospital de São Francisco Xavier, Centro Hospitalar de Lisboa Ocidental, Estrada do Forte do Alto do Duque, 1449-005, Lisboa, Portugal (e-mail: carla.ricardonunes@gmail.com).
\end{abstract}

Rev Iberam Cir Mano 2020;48:56-60.

\author{
Abstract \\ Keywords \\ - dorsal radiocarpal \\ ligament \\ - ligament tear \\ - arthroscopic repair

\section{Resumen}

\section{Palabras clave} \\ - ligamento dorsal \\ radiocarpiano \\ - rotura de ligamentos \\ - reparación \\ artroscópica
}

The dorsal radiocarpal ligament (DRCL) is a dorsal capsular ligament with a significant role in carpal stability. We should consider the arthroscopic repair of the DRCL in cases of isolated DRCL tear or when the DCRL tear is the only clinically evident injury. Arthroscopic view of the DRCL tear is better through the volar radial portal. The purpose of the present article is to describe three cases of uncommon DRCL tear in patients with chronical dorsal wrist pain that were treated by arthroscopic repair. This condition can easily be unrecognized by the orthopedic surgeon if it is not specifically searched for. Good results are expected following the arthroscopic repair of an isolated DRCL tear; however, the contribution of the DRCL to the final outcome in combined repairs is difficult to isolate.

El ligamento dorsal radiocarpiano (LDRC) es un ligamento dorsal capsular con un papel importante en la estabilidad del carpo. Debemos considerar la reparación mediante artroscopia del LDRC en casos de rotura aislada de este ligamento o cuando la rotura de LDRC es la única lesión clínicamente evidente. La mejor visualización artroscópica de este ligamento se realiza a través del portal volar radial. El objetivo de este trabajo es describir tres casos clínicos raros de lesión aislada de LDRC en pacientes con dolor crónico en el dorsal de la muñeca tratados mediante reparación artroscópica. Esta patología fácilmente pasa desapercibida para el ortopedista si no se busca específicamente. Podemos esperar buenos resultados con la reparación artroscópica de la lesión de LDRC aislada; sin embargo, la contribución de la reparación de la lesión de LDRC al resultado final del tratamiento cuando hay lesiones asociadas es difícil de valorar. received

September 29, 2019

accepted

January 14,2020
DOI https://doi.org/

$10.1055 / \mathrm{s}-0040-1708462$ ISSN 1698-8396.
Copyright $\odot 2020$ Thieme Revinter

Publicações Ltda, Rio de Janeiro, Brazil
License terms

(c) $(1) \$$ 


\section{Introduction}

The dorsal radiocarpal ligament (DRCL) is important in carpal stability. ${ }^{1,2}$ The DRCL is a dorsal capsular ligament of the wrist; it originates from the distal radius, just ulnar and distal to Lister's tubercle, and extends to the ulnar horn of the lunate and to the distal region of the lunotriquetral ligament (LTL), inserting onto the tubercle of the triquetrum. ${ }^{2}$ The dorsal intercarpal ligament (DIC) originates from the triquetrum and extends radially to attach to the lunate, the dorsal groove of the scaphoid, and then the trapezium. ${ }^{2}$ The DRCL and DIC have a lateral V configuration that works like a dorsal radioscaphoid ligament, allows normal carpal kinematics, and provides stability to the scaphoid over the full arc of wrist motion. ${ }^{2,3}$ Tears of the DRCL have been related to the development of volar intercalated segmental instability (VISI), dorsal intercalated segmental instability (DISI) and may be involved in the development of midcarpal instability. $1,3,4$

We have to consider the arthroscopic repair of the DRCL in isolated DRCL tears and in cases when the associated lesions are treated, such as when the scapholunate interosseous ligament (SLIL) is debrided and/or pinned; and in ulnar-sided pathology, like lunotriquetral ligament tears and triangular fibrocartilage complex tears. ${ }^{5}$ The contribution of the DRCL to the final outcome in combined repairs, however, is difficult to isolate.

The DRCL is difficult to visualize through the standard dorsal wrist arthroscopy portals. The torn edge of the DRCL tends to float up against the arthroscope while viewing through the 3-4 portal but can be seen obliquely through the 1-2 and $6 \mathrm{U}$ portal. The best view of the DRCL is through the volar radial portal. ${ }^{6-8}$

The purpose of the present article is to describe three cases of uncommon DRCL tear that were treated by arthroscopic repair with good results.

\section{Clinical Case}

\section{Case 1}

A 29-year-old male patient, professional futsal player and supermarket cashier, went to the clinic because he had a left wrist pain for 17 months. He referred a trauma with hyperextension of the wrist while playing futsal. Upon physical examination, he had dorsal wrist pain, radial styloid pain, and dorsal-volar carpal translation. There was no visible deformity or neurovascular deficit. The anteroposterior (AP) and lateral radiographs were normal. An ultrasound showed an extensor tenosynovitis and dorsal capsule-ligament thickening. A magnetic resonance imaging (MRI) showed a dorsal heterogeneous hyperdensity of the radiocarpal interface compatible with distension of the DRCL, fluid in the carpus, and slight anteversion of the scaphoid and posttraumatic ligament lability between the deep ligament structures of the carpus. An arthro-computed tomography (CT) was requested to confirm the diagnosis, which showed the presence of disruption of the dorsal articular capsule,

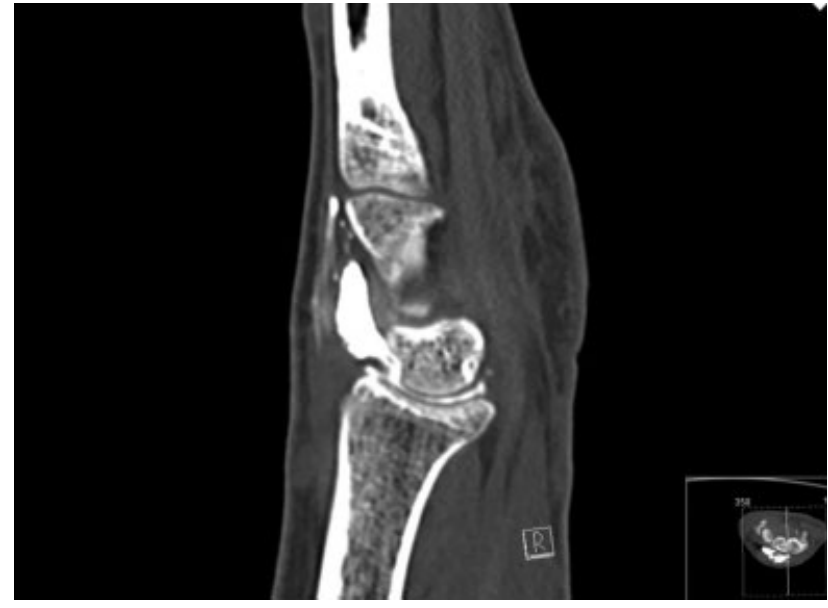

Fig. 1 Arthro-computed tomography, case 1.

involving the DRCL, without other lesions (-Fig. 1). The patient failed a trial of splinting and activity modification. He was proposed for arthroscopic repair.

\section{Case 2}

A 33-year-old female patient, casino worker, went to the clinic because she had a right wrist pain for 7 months, after a traffic accident. Upon physical examination, she had dorsal wrist pain. There was no visible deformity or neurovascular deficit. The AP and lateral radiographs were normal. She performed an MRI that showed edema of the DRCL, possibly related to stretch. The patient failed a trial of splinting and activity modification. She was proposed for arthroscopic repair.

\section{Case 3}

A 31-years-old male, forklift driver, went to the clinic because he had a wrist pain for 9 months. He referred a trauma with hyperextension of the wrist. Upon physical examination, he had radial wrist pain and dorsal-volar carpal translation. There was no visible deformity or

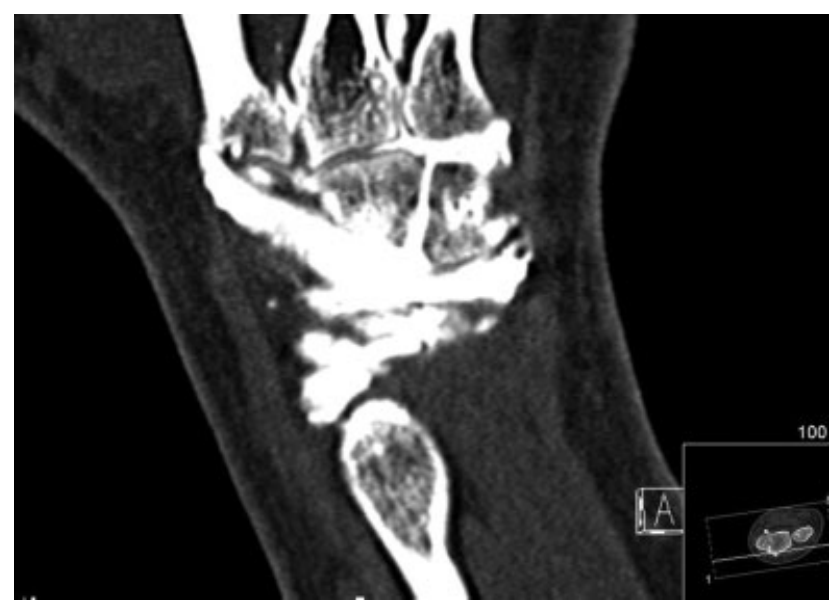

Fig. 2 Arthro-computed tomography, case 3. 


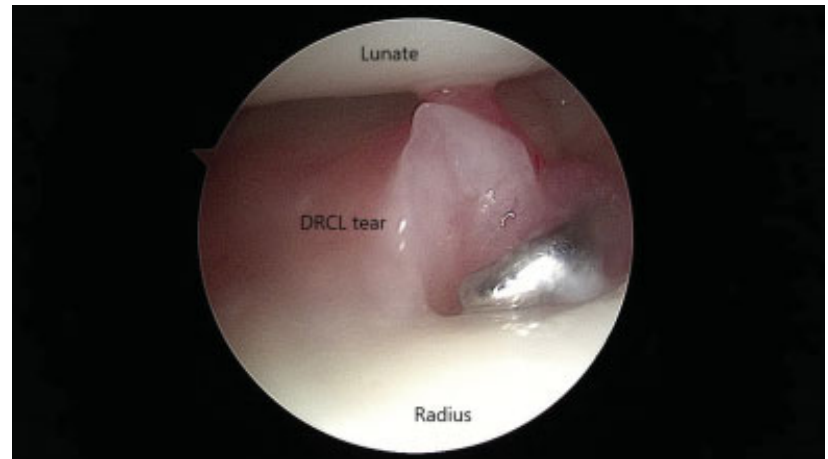

Fig. 3 Volar radial portal, dorsal radiocarpal ligament tear view.

neurovascular deficit. The AP and lateral radiographs and ultrasound were normal. He performed an MRI, which raised the suspicion of DRCL lesion without another ligament injury. An arthro-CT was requested to confirm the diagnosis, which showed a presence of disruption of the DRCL and of the scapholunate and lunotriquetral interosseous ligaments too (-Fig. 2). The patient failed a trial of splinting and activity modification. He was proposed for arthroscopic repair.

\section{Surgical Technique}

We used the outside-in technique described by Slutsky. ${ }^{4-6}$ Under tourniquet control, the patient's arm is suspended in a traction tower, the dorsal portals $(3-4,4-5,6 \mathrm{R}, 6 \mathrm{U}$ and radial e ulnar midcarpal portals) and volar radial portal are established. The DRCL is observed just ulnar to the 3-4 portal underneath the lunate, and the hook probe reveals the torn edge of the ligament (-Fig. 3). A 3-0 absorbable suture is passed through a needle that is introduced through the 4-5 portal, running across the ligament, and the end of the suture

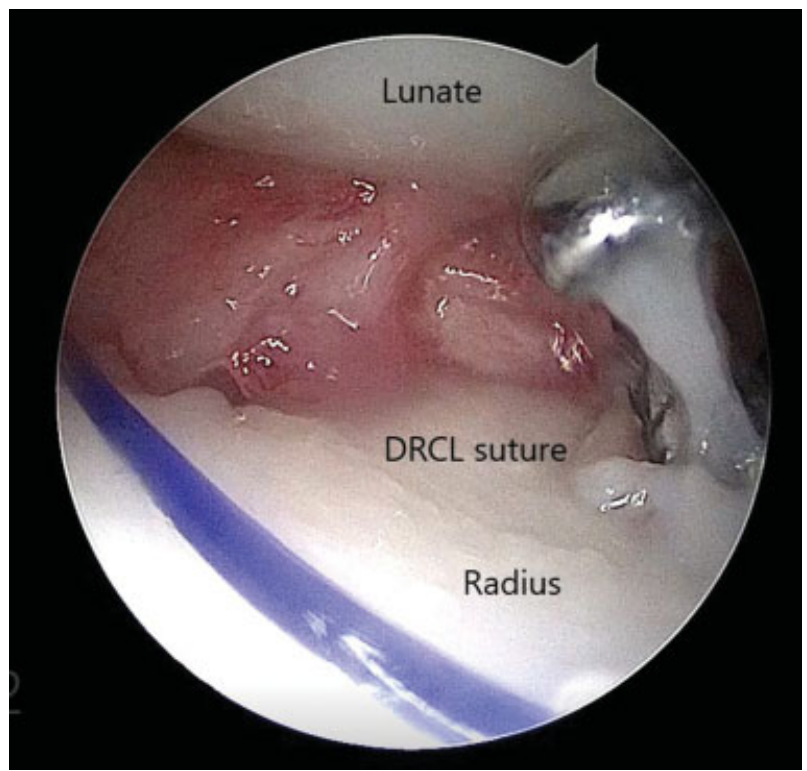

Fig. 4 Ongoing ligament suture.

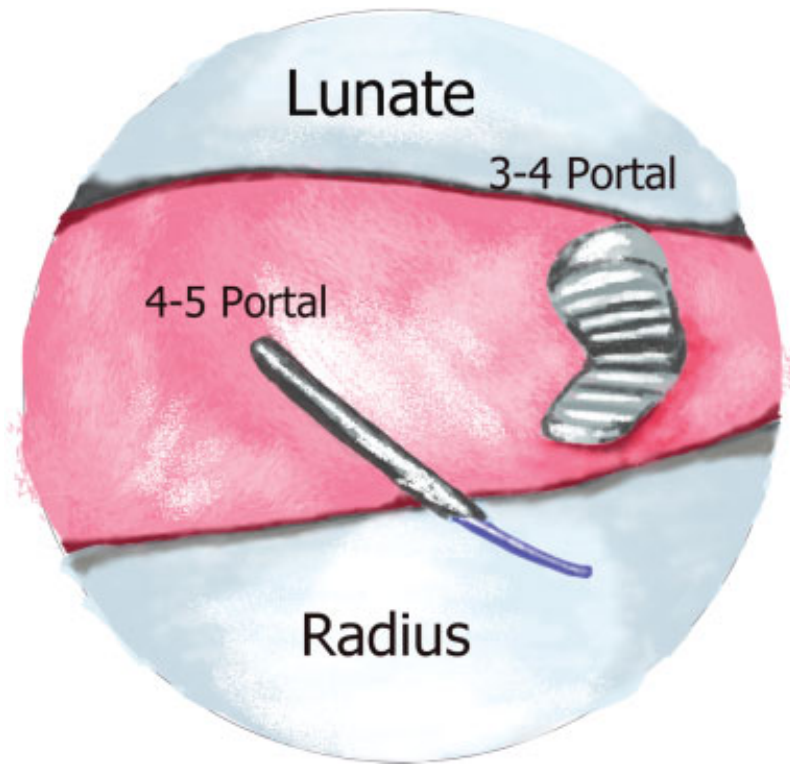

Fig. 5 Schematic view of the DRCL suture technique.

is retrieved with a grasper in the 3-4 portal ( $\mathbf{- F i g s . ~} \mathbf{4}$ and $\mathbf{5}$ ). After both ends of the suture are withdrawn, dorsal traction can be seen to pull the torn edge of the DRCL up against the dorsal capsule (-Fig. 6). The suture is passed under the extensor tendons and tied at either dorsal portal after releasing traction. Case 1 was performed under dry arthroscopy. There was dorsal synovitis and no other injuries. Case 2 was performed with saline infusion; there was a lunotriquetral interosseous ligament tear Geissler II, which was addressed by lunotriquetral pinning. Case 3 was performed with dry arthroscopy; we found a scapholunate interosseous ligament tear Geissler II, which was repaired by arthroscopic

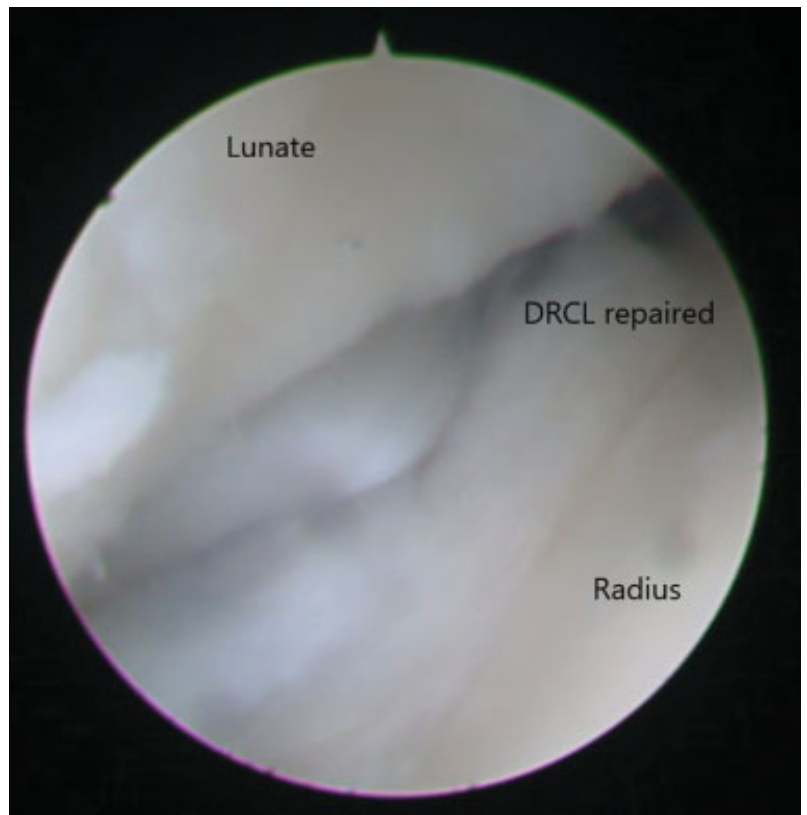

Fig. 6 Ligament repaired. 
Table 1 Classification of dorsal radiocarpal ligament tears

\begin{tabular}{|l|l|}
\hline Stage & Description \\
\hline 1 & Isolated DRCL tear \\
\hline 2 & $\begin{array}{l}\text { DRCL tear with associated SLIL or LTIL } \\
\text { (Geissler I/II) or TFCC tear or midcarpal instability }\end{array}$ \\
\hline $3 \mathrm{~A}$ & $\begin{array}{l}\text { DRCL tear with associated SLIL or LTIL } \\
\text { (Geissler III) and/or TFCC tear }\end{array}$ \\
\hline 4 & $\begin{array}{l}\text { DRCL tear with associated SLIL or LTIL } \\
\text { (Geissler IV) and/or TFCC tear }\end{array}$ \\
\hline $\begin{array}{l}\text { DRCL tear with chondromalacia or } \\
\text { widespread degenerative changes }\end{array}$ \\
\hline
\end{tabular}

Abbreviations: DRCL, dorsal radiocarpal ligament; LTIL, lunotriquetral interosseous ligament; SLIL, scapholunate interosseous ligament; TFCC, triangular fibrocartilage complex.

dorsal capsule-ligamentous repair as described by Mathoulin et al. ${ }^{9}$

\section{Postoperative, Rehabilitation and Follow-up}

After surgery, the patients are placed in a short arm sugar tong cast with the wrist in neutral rotation for 6 weeks. Wrist motion with use of a removable splint for comfort is instituted after cast removal. Gradual strengthening exercises were added after 8 to 10 weeks. At 6 months postoperatively, the patients performed their work activities without limitation and, in case 1 , sport activity at $100 \%$. The quick Disabilities of the Arm, Shoulder and Hand (DASH) score was 29.5 at 6 months after the surgery. Case 2 had a minor flexion loss without impact in her daily life. The patient returned 3 years later with unrelated symptoms and had a new MRI done that showed healing of the DRCL and no synovitis or carpal injury. Case 3 recovered full range of motion, returned to work at 3 months after the surgery, and the quick DASH score was 22 at 4.5 months after the surgery.

\section{Discussion}

The incidence of DRCL tears is not known. ${ }^{3}$ This can be related to the fact that it is difficult to visualize the DCRL through the standard dorsal wrist arthroscopy portals. ${ }^{3}$ In a study of Slutsky, 35 of the 64 patients with wrist pain had a DRCL tear and only 5 had an isolated DRCL tear. ${ }^{4}$ An arthroscopic staging scheme for DRCL tears has been proposed (-Table $\mathbf{1}$ ), depending on whether it is a lesion isolated from the DRCL or associated with lesions of other structures, namely the scapholunate interosseous ligament, lunotriquetral interosseous ligament or triangular fibrocartilage complex. ${ }^{3,5}$ Although the natural history of these DRCL tears is not known, in a study of Slutsky, the patients with an isolated DRCL tears had the most duration of pain, with a median time of 36 months, whereas the group with associated intracarpal pathology had pain for 12 months. ${ }^{4}$ They concluded that even though the numbers are small, it is apparent that an isolated DRCL tear does not necessarily lead to other intracarpal ligament or triangular fibrocartilage complex (TFCC) tears. ${ }^{4}$ An arthroscopic repair is indicated for isolated DRCL tears because it can provide favorable outcomes. ${ }^{3,6,10}$ Furthermore, Elsaidi demonstrated the importance of the DCRL on scaphoid kinematics through a series of sectioning studies, concluding that when the DRCL was divided, a DISI deformity occurred. ${ }^{11}$

Short, in cadaveric studies, detected that either a dorsal capsulotomy sectioning the dorsal radiocarpal ligament or insertion of the pressure sensor alters the scaphoid and lunate kinematics during dynamic wrist motion, supporting the idea that the dorsal wrist ligament should be spared during surgical approaches to the carpus. ${ }^{1}$

In case 1 , the isolated DRCL rupture, we obtained a good postoperative quick DASH score, although we cannot quantify the improvement because we did not have the preoperative score. This good result is in line with the literature.

This condition can easily be missed by the orthopedic surgeon unless there is a high degree of suspicion and it is actively looked for before and during arthroscopy. Good results are expected following the arthroscopic repair of an isolated DRCL tear, however he contribution of the DRCL to the final outcome in combined repairs is difficult to isolate. It is arguable whether the DRCL repair changes the final result when other ligament injuries are the primary diagnosis.

Conflict of Interests

The authors have no conflict of interests to declare.

\section{References}

1 Short WH, Werner FW, Green JK, Weiner MM, Masaoka S. The effect of sectioning the dorsal radiocarpal ligament and insertion of a pressure sensor into the radiocarpal joint on scaphoid and lunate kinematics. J Hand Surg Am 2002;27(01): 68-76

2 Viegas SF, Yamaguchi S, Boyd NL, Patterson RM. The dorsal ligaments of the wrist: anatomy, mechanical properties, and function. J Hand Surg Am 1999;24(03):456-468

3 Slutsky DJ. Incidence of dorsal radiocarpal ligament tears in the presence of other intercarpal derangements. Arthroscopy 2008; 24(05):526-533

4 Slutsky DJ. The incidence of dorsal radiocarpal ligament tears in patients having diagnostic wrist arthroscopy for wrist pain. J Hand Surg Am 2008;33(03):332-334

5 Slutsky DJ. Arthroscopic Dorsal Radiocarpal Ligament Repair. Principles and Practice of Wrist Surgery 2010. Chapter 46: 492-497

6 Slutsky DJ. Arthroscopic repair of dorsal radiocarpal ligament tears. Arthroscopy 2002;18(09):E49

7 Slutsky DJ. Arthroscopy portals: volar and dorsal. In Budoff J, Slade JF, Trumble TE: Master's Techniques in Wrist and Elbow Arthroscopy. Chicago: American Society for Surgery of the Hand, 2006

8 Slutsky DJ. Wrist arthroscopy through a volar radial portal. Arthroscopy 2002;18(06):624-630

9 Mathoulin C, Dauphin N, Sallen V. Arthroscopic dorsal capsuloplasty in chronic scapholunate ligament tears: a new 
procedure; preliminary report. Chir Main 2011;30(03): 188-197

10 Slutsky DJ. Arthroscopic management of dorsoradiocarpal ligament repairs. J Hand Surg Am 2005;(05):167-174
11 Elsaidi GA, Ruch DS, Kuzma GR, Smith BP. Dorsal wrist ligament insertions stabilize the scapholunate interval: cadaver study. Clin Orthop Relat Res 2004; (425):152-157 